\title{
HET TWEESLACHTIG KARAKTER VAN DE CONVERTEERBARE OBLIGATIE; ENKELE OPMERKINGEN OVER HET CONVERSIE-AGIO OF DE PREMIE*)
}

\section{door Drs. L. van Klinken}

Het tweeslachtig karakter van de converteerbare obligatie kan naar onze mening het best benaderd worden aan de hand van de begrippen obligatiewaarde en conversiewaarde van de obligatie.

Onder de obligatiewaarde (de "straight debt value") van deze obligatie wordt verstaan de waarde zonder het conversierecht; de waarde als zuivere obligatie dus.

De conversiewaarde van deze obligatie wordt aangeduid door de waarde van het aandeel (of de aandelen), die op een bepaald moment uit de omwisseling ervan kan worden verkregen. Zo bedraagt de conversiewaarde van een obligatie van $f 1.000$,- omwisselbaar in één aandeel van $f 1.000$,- onder bijstorting van $f 500,-$ in contanten bij een koers van het aandeel van $200 \%$ $f 1.500,-$. De obligatie zal op grond van deze getallenverhoudingen tenminste $150 \%$ noteren.

De obligatiewaarde wordt hoofdzakelijk bepaald door de rente, welke op de lening wordt betaald in vergelijking met de algemene rentestand, of met de rente betaald op een waardepapier uit dezelfde risicoklasse en met een overeenkomstige looptijd.

Deze waarde zal doorgaans in de buurt van $100 \%$ liggen, behoudens een rentedaling of rentestijging. Daalt $\mathrm{nl}$. de rentestand, dan zal de obligatie boven pari gaan noteren, in geval van rentestijging zal zij beneden pari gaan noteren.

Naarmate de converteerbare obligatie verder boven de obligatiewaarde noteert, neemt het aandeelkarakter ervan toe en dus de conversiewaarde. We kunnen nu stellen, dat de waarde van de converteerbare obligatie bepaald wordt door de obligatiewaarde of door de conversiewaarde en wel door de hoogste van de twee.

Nu blijkt in de praktijk, dat de converteerbare obligatie vrijwel steeds een waarde heeft, welke boven de hoogste van de beide genoemde waarden gelegen is. Het verschil tussen de marktwaarde en de hoogste van de twee wordt conversie-agio of premie genoemd. Aan de verklaring van deze premie, zullen wij in dit artikel aandacht schenken. De premie kan, naar in de praktijk kan worden waargenomen uitgedrukt in procenten van de koerswaarde van de obligatie, wel een grootte aannemen van $20 \%$ en zelfs daarboven.

Brigham') noemt een drietal redenen waarom hij ervan uitgaat, dat naarmate de koers van de converteerbare obligatie stijgt als gevolg van de stijging van de koers van het aandeel, de premie afneemt. De eerste en, aldus Brigham, waarschijnlijk de meest belangrijke is het verlies, dat zal ontstaan, indien de obligatie vervroegd aflosbaar wordt gesteld. De obligatiehouder kan nu de aflossingswaarde ontvangen dan wel hij kan zijn obligatie omwisselen

\footnotetext{
*) Bij de totstandkoming van dit artikel is medewerking verleend door Drs. H. Samuels Brusse, die in 1972 afstudeerde in de Faculteit der Wiskunde en Natuurwetenschappen van de R.U. Leiden.
} 
in aandelen of verkopen. De obligatie zal dus ingeval zij aflosbaar wordt gesteld een waarde aannemen, welke gelijk is aan de conversiewaarde. De obligatiehouder zal, indien de conversiewaarde ligt boven de aflossingswaarde van de obligatie tot omwisseling overgaan, daar hij anders een koersverlies zal moeten incasseren ter grootte van het verschil tussen de conversie- en aflossingswaarde. De mogelijkheid, dat de obligatie vervroegd wordt afgelost is er nu debet aan, dat de obligatiehouder de kans loopt de premie te zullen verliezen.

Naarmate de koers van de converteerbare obligatie stijgt wordt de kans groter, dat zij vervroegd wordt afgelost en neemt de kans op het verlies van de premie dus ook toe.

De tweede reden, welke Brigham noemt ter verklaring van het verschijnsel, dat naarmate de obligatie in koers stijgt, de waarde ervan gelijk wordt aan de conversiewaarde, heeft betrekking op het verliesbeperkend karakter van de converteerbare obligatie.

Dit verliesbeperkend karakter (bestaande uit de omstandigheid, dat het mogelijke verlies op de obligatie kleiner is dan dat op het aandeel wegens de obligatiewaarde als tweede ondergrens) gaat steeds minder een rol spelen naarmate de obligatie in koers stijgt; naarmate zij dus meer het karakter van aandeel gaat aannemen.

De derde reden, welke tenslotte genoemd wordt is gelegen in rendementsoverwegingen. Het aandeel zal blijvend een hogere koers noteren, indien de winsten/dividenden van de N.V. toenemen, waardoor ook de converteerbare obligatie in koers zal stijgen. Daar de rente, die op de obligatie wordt betaald een vast bedrag per jaar is, zal bij stijging van de koers het rendement er op afnemen.

\section{Nadere beschouwing van de premie}

Niet alle auteurs definiëren de premie zoals in het voorgaande is gebeurd. Baumol, Malkiel en Quandt ${ }^{2}$ ) onderscheiden twee premies; één die gevormd wordt door de waarde boven de obligatiewaarde en één, die gevormd wordt door de waarde boven de conversiewaarde. Dit onderscheid is het gevolg van het feit, dat ook de premie een tweeslachtig karakter heeft, nl. het karakter van een garantie, indien de conversiewaarde van de obligatie hoger is dan de obligatiewaarde en het karakter van een optie ( $\mathrm{nl}$. het conversierecht of conversie-optie), indien de obligatiewaarde hoger is dan de conversiewaarde.

Weil, Segall en Green ${ }^{3}$ ) spreken alleen over de premie als het verschil tussen de marktwaarde van de obligatie en de conversiewaarde. $\mathrm{Zij}$ laten de obligatiewaarde alleen een rol spelen in de premie zelf. D.w.z. is de obligatiewaarde hoger dan de conversiewaarde dan zit het verschil tussen de obligatiewaarde en de conversiewaarde in de premie opgesloten. Wat betreft de verklaring van het verschijnsel, dat de converteerbare obligatie een waarde heeft, welke uitgaat boven de obligatie- of conversiewaarde, kan het volgende naar voren gebracht worden. Indien de conversiewaarde hoger is dan de obligatiewaarde kan de premie verklaard worden uit de omstandigheid, dat de obligatie in tegenstelling met een gewoon aandeel de garantie biedt, dat, wat de 
koers van het aandeel en daarmede de conversiewaarde ook moge doen, tenminste de obligatiewaarde behouden blijft. De converteerbare obligatie wordt in deze gedachtengang opgevat als een gewoon aandeel, dat echter voorzien is van een garantie, om welke reden zij een hogere waarde heeft dan het aandeel (of de conversiewaarde). Deze hogere waarde nu is de premie. Indien de obligatiewaarde hoger is dan de conversiewaarde vindt de premie zijn verklaring in de omstandigheid, dat de converteerbare obligatie in vergelijking met een gewone obligatie een conversierecht of optie bezit, dus iets meer bezit dan een gewone obligatie.

De converteerbare obligatie wordt in deze gedachtengang opgevat als een gewone obligatie, voorzien van conversierecht, om welke reden zij een hogere waarde heeft dan de gewone obligatie (of de obligatiewaarde). Ter illustratie van de garantie en het conversierecht geven wij het volgende voorbeeld. Stel, dat een obligatie van nominaal $f 1.000,-$ omwisselbaar is in drie gewone aandelen van elk nominaal groot $f 100,-$. Indien de koers van het aandeel $400 \%$ bedraagt, is de conversiewaarde $f 1.200$,- . Wanneer nu de koers van het aandeel daalt tot $300 \%$, bedraagt de conversiewaarde $f 900,-$. De houder van de drie aandelen heeft dan een bezit, dat $f 900,-$ waard is, terwijl de houder van de converteerbare obligatie nog altijd een effect in handen heeft, welke tenminste een aflossingswaarde van $f 1.000,-$ heeft. Zijn verlies is dus beperkter dan dat van de houder der drie gewone aandelen. Stel nu, dat de koers van hht aandeel $3331 / 3 \%$ bedraagt, dan is de conversiewaarde van de obligatie $f 1.000,-$.

Wanneer de koers van het aandeel stijgt tot $400 \%$, loopt de conversiewaarde op tot $f 1.200$,- . De houder van een gewone obligatie van $f 1.000$,nominaal heeft een bezit, dat, afhankelijk uiteraard van de koers van de obligatie, een waarde heeft van, laten we zeggen $f 1.000,-$, terwijl de houder van de converteerbare obligatie een papier in handen heeft met een waarde van $f 1.200,-$. Hij kan zijn obligatie omwisselen en bezit dan aandelen ter waarde van $f 1.200,-$. Zijn conversierecht vertegenwoordigt in dit geval dus een waarde van $f 200,-$.

Naar vermeld, neemt de premie af naarmate de conversiewaarde hoger wordt. Theoretisch is de premie het hoogst, daar, waar de obligatiewaarde en de conversiewaarde aan elkaar gelijk zijn of anders gezegd, daar, waar de verhouding conversiewaarde en obligatiewaarde het dichtst bij 1 ligt. De verklaring hiervoor is naar onze mening, dat, naarmate de conversiewaarde dichter bij de obligatiewaarde ligt, de garantie de grootste betekenis heeft. En de garantie heeft dan de grootste betekenis, omdat de kans, dat de conversiewaarde onder de obligatiewaarde daalt het grootst is, indien de verhouding tussen deze beide waarden ongeveer gelijk aan één is; indien dus de conversiewaarde dicht bij de obligatiewaarde ligt.

Een kleine daling van de koers van het aandeel kan dan de conversiewaarde doen dalen tot beneden de obligatiewaarde. Het zal tevens duidelijk zijn, dat de waarde van de premie groter is naarmate de koers van het aandeel aan grotere schommelingen onderhevig is. In dat geval is nl. de kans, dat de conversiewaarde beneden de obligatiewaarde komt te liggen groter, hetgeen de garantie weer een grotere betekenis geeft. Anderzijds kan worden gesteld, 
dat naarmate de kans groter is, dat de conversiewaarde boven de obligatiewaarde stijgt, het conversierecht een grotere betekenis krijgt, hetgeen de premie in waarde zal doen toenemen.

Wij hebben tot dusver twee factoren genoemd, welke van belang zijn voor de hoogte van de premie, nl. de verhouding tussen de obligatiewaarde en de conversiewaarde en de mate, waarin het aandeel aan koersschommelingen onderhevig is. Er is nog een factor te noemen.

Zo vormt de tijd, die resteert eer de converteerbare obligatie wordt afgelost of de tijd, die resteert eer verwacht wordt dat de bestuurders der N.V. conversie zullen afdwingen, een factor, die de hoogte van de premie zal beïnvloeden.

Naarmate nl. de tijd tot de aflossing of de verwachte conversie langer is, is de kans, dat de conversiewaarde in de toekomst boven de obligatiewaarde uit zal stijgen of omgekeerd groter, zodat het conversierecht (of in het andere geval de garantie) in betekenis toeneemt en dus de premie hoger zal zijn. Omgekeerd zal de premie afnemen, indien deze tijd kleiner is. Naar onze mening zijn de drie genoemde factoren, $\mathrm{nl}$. de verhouding van de conversiewaarde en de obligatiewaarde, de mate, waarin het aandeel aan koersschommelingen onderhevig is en de tijd, die nog resteert tot de obligatie wordt afgelost dan wel wordt geconverteerd, bepalend voor de waarde van de garantie en de waarde van het conversierecht en derhalve voor de hoogte van de premie.

Weil, Segall en Green $^{3}$ ) noemen de volgende factoren, die volgens hen bepalend zijn voor de hoogte van de premie:

1 de transaktiekosten. Deze kosten zijn in geval een obligatie wordt gekocht aanzienlijk lager dan wanneer men een aandeel koopt. $\mathrm{Zij}$ noemen de bedragen geldend voor de Verenigde Staten, nl. $\$ 2.50$ voor een obligatie en $\$ 15$. - voor een equivalent aantal aandelen. Om een aandeel te bemachtigen zou het voordeliger zijn de converteerbare obligatie te kopen en haar om te wisselen in aandelen, hetgeen dan een besparing betekent op de transaktiekosten. Op grond hiervan zou de converteerbare obligatie tenminste een premie hebben ter grootte van het verschil in transaktiekosten bij aankoop van aandelen en bij aankoop van de obligatie, die in de aandelen omwisselbaar is.

2 de verschillen in inkomsten van de converteerbare obligatie en van de equivalente aandelen. Indien de rente op de obligatie hoger is dan het dividend op de equivalente aandelen, zal dit verschil in inkomsten tot uitdrukking moeten komen in de premie. In het omgekeerde geval is de premie ook aanwezig, maar heeft dan een negatieve waarde. De hoogte van de premie zal evenredig moeten zijn aan het verschil in rente op de obligatie en het dividend op de aandelen.

3 het verschil in financieringsmogelijkheden van converteerbare obligaties en aandelen. $\mathrm{Zij}$ vermelden, dat voor de aankoop van obligaties leningen kunnen worden verkregen van 70 tot $90 \%$ van de aankoopsom, terwijl dit percentage voor de aankoop van aandelen in de Verenigde Staten slechts $30 \%$ bedraagt. Door de werking van het hefboomeffect wordt op deze wijze een hoger rendement op het eigen geïnvesteerd vermogen verkre- 
gen, hetgeen het kopen van converteerbare obligaties dus aantrekkelijker maakt, op grond waarvan deze obligaties een premie moeten bezitten ter hoogte van het grotere rendement. Een andere factor, die wij hier niet onvermeld laten, is het feit, dat institutionele beleggers gebonden zijn aan voorschriften, die het beleggen in aandelen aan banden legt; converteerbare obligaties worden hierdoor voor hen aantrekkelijker. Ze kopen dan obligaties met een aandeelachtig karakter.

4 de anti-verwateringsclausule. Hierover wordt door hen alleen gezegd, dat naarmate de converteerbare obligatie voorzien is van een betere anti-verwateringsclausule, de waarde van de obligatie hoger zal zijn, hetgeen in de premie tot uitdrukking zal moeten komen.

5 de prijsbodem. Hieronder verstaan zij de omstandigheid, dat een converteerbare obligatie in tegenstelling met het aandeel een minimumprijs bezit, waarbeneden zij niet zal dalen. Deze bodem verschaft de obligatie een premie, die het aandeel niet bezit. De premie zou dan gelijk moeten zijn aan het verschil tussen de bodemprijs van de converteerbare obligatie en de prijs van een gewone obligatie van gelijke risicoklassen en gelijke kwaliteit.

Het begrip prijsbodem van Weil, Segall en Green zouden wij niet tot de factoren willen rekenen, die de premie bepalen. In plaats daarvan hebben wij als medebepalend factor genoemd de verhouding van de conversiewaarde en de obligatiewaarde. Weil, Segall en Green beschouwen als premie de waarde van de obligatie, welke uitgaat boven de conversiewaarde, ook als de obligatiewaarde groter is dan de conversiewaarde. Wij nemen het begrip prijsbodem niet over, omdat wij van mening zijn, dat met de drie door ons behandelde factoren, die de hoogte van de premie bepalen, zowel de waarde van de garantie als de waarde van het conversierecht afdoende kunnen worden beschreven.

6 de mate, waarin het aandeel aan koersschommelingen onderhevig is. Deze factor hebben wij in het voorgaande reeds beschreven.

7 de tijd, die resteert voor de obligatie wordt afgelost dan wel wordt geconverteerd. Ook deze factor hebben wij in het voorgaande voldoende besproken.

Inzake de eerste vier punten, die Weil, Segall en Green noemen, kunnen wij opmerken, dat kwantificering van de invloed van financieringsmogelijkheden en de aanwezigheid van een goede anti-verwateringsclausule op de hoogte van de premie niet gemakkelijk uitvoerbaar is. Van de eerste vier door hen genoemde punten blijven nog twee over, nl.:

1 het verschil in transaktiekosten

2 het verschil in inkomsten.

De hoogte van de premie kan naar onze mening echter niet uitsluitend verklaard worden uit het verschil in transaktiekosten of het verschil in inkomsten tussen het aandeel en de converteerbare obligatie. Het verschil in inkomsten tussen het aandeel en de converteerbare obligatie wordt door Weil, Segall en Green ter verklaring van de hoogte van de premie wel genoemd, maar zij maken niet aannemelijk dat er tussen de beide waardepapieren inkomstenverschillen van betekenis zijn. 
Ook kunnen naar onze mening de grotere financieringsmogelijkheden van de obligatie of een betere anti-verwateringsclausule, een premie van $20 \%$ of zelfs meer niet rechtvaardigen. Deze factoren zullen ongetwijfeld een rol spelen. Wij leggen ter verklaring van de hoogte van de premie de nadruk op de volgende punten:

1 in welke mate is het aandeel aan koersschommelingen onderhevig

2 de verhouding conversiewaarde en obligatiewaarde

3 de tijd, die resteert tot het moment van a flossing of conversie.

Bij de beschouwing over deze drie factoren hebben wij steeds de waarde van de garantie en de waarde van het conversierecht gekarakteriseerd door de kans, dat de conversiewaarde de obligatiewaarde overschrijdt dan wel daaronder komt. Hiermee wordt $\mathrm{nl}$. de kans aangegeven, dat de converteerbare obligatie ten opzichte van het aandeel haar verliesbeperkend karakter toont, respectievelijk conversie van de obligatie in aandelen tot onmiddellijke koerswinst leidt. Het is echter niet alleen de vraag hoe waarschijnlijk het is, dat de conversiewaarde de obligatiewaarde overschrijdt dan wel daaronder komt, ter bepaling van de hoogte van de premie. Men zal zich ook moeten afvragen hoever deze overschrijding (of het tegengestelde) zal kunnen gaan om een converteerbare obligatie op een bepaald moment te waarderen en de hoogte van de premie vast te stellen. Ook bij deze vraag spelen naar onze mening de drie genoemde factoren een belangrijke rol.

Het is intussen geen eenvoudige zaak deze factoren in een formule te vangen, in welke formule de waarde van de converteerbare obligatie als functie van deze drie factoren kan worden weergegeven.

\section{De converteerbare obligatie in vergelijking met het gewone aandeel, waaraan een stop- loss-order is verbonden}

Weil, Segall en Green ${ }^{3}$ ) komen tot de conclusie, dat ,there is no place for a floor any larger than the expected cost of executing a stop-sell order. The determination of the premium depends, we suggest, entirely on the differences in the expected cash streams, but the calculation of the expected cash streams is the whole problem of security evaluation". $\mathrm{Zij}$ komen dus tot een andere conclusie dan wij. Zij zijn van mening dat de verliesbeperkende garantie, die de converteerbare obligatie biedt, ook verkregen kan worden door de aankoop van gewone aandelen, waaraan een stop-loss-order is verbonden. Een stop-loss-order houdt in, dat de aandelen worden verkocht, zodra de koers daalt tot een bepaald niveau, het niveau van de zgn. ,trigger-price" van de stop-loss-order. Wanneer nu deze ,trigger-price" gelijk wordt gesteld aan de obligatiewaarde van de converteerbare obligatie, zou men, aldus Weil, Segall en Green, hetzelfde verliesbeperkende effect bereiken. De garantie die de converteerbare obligatie biedt, mag dan ook volgens hen slechts een waarde bezitten, die gelijk is aan de kosten verbonden aan een stop-loss-order, te weten:

1 de kosten van het uitvaardigen van de order

2 de provisie voor het uitvaardigen van de order 
3 het verlies, dat ontstaat, indien de aandelen worden verkocht voor een prijs, die onder de "trigger-price" is gelegen.

Weil, Segall en Green komen dan ook tot de conclusie, dat de garantie een geringe rol speelt bij de bepaling van de premie, maar dat de hoogte ervan in hoofdzaak bepaald wordt door het verschil in inkomsten van de obligatie en het aandeel. De moeilijkheid achten zij gelegen in het bepalen van de waarde van dit inkomstenverschil.

We willen de waarde van het derde onderdeel van de kosten verbonden aan een stop-loss-order niet onderschatten.

Wanneer elke aandeelhouder nl. een stop-loss-order uitvaardigt met dezelfde ,trigger-price", zal het aanbod van aandelen, indien de koers van het aandeel beneden deze prijs daalt, dermate groot zijn, dat de uiteindelijke verkoopprijs van het aandeel ver beneden bedoelde „trigger-price" zal komen te liggen.

Er bestaat echter verschil tussen de converteerbare obligatie en het aandeel voorzien van een stop-loss-order o.m. wat betreft het beperken van het risico van verlies. Beide beperken het risico van verlies, maar de stop-loss-order veroorzaakt ook een winstbeperkend effect, dat niet optreedt bij de converteerbare obligatie, zodat deze obligatie meer voordelen biedt dan een aandeel voorzien van een stop-loss-order. Een en ander zullen wij verduidelijken aan de hand van onderstaande grafiek.

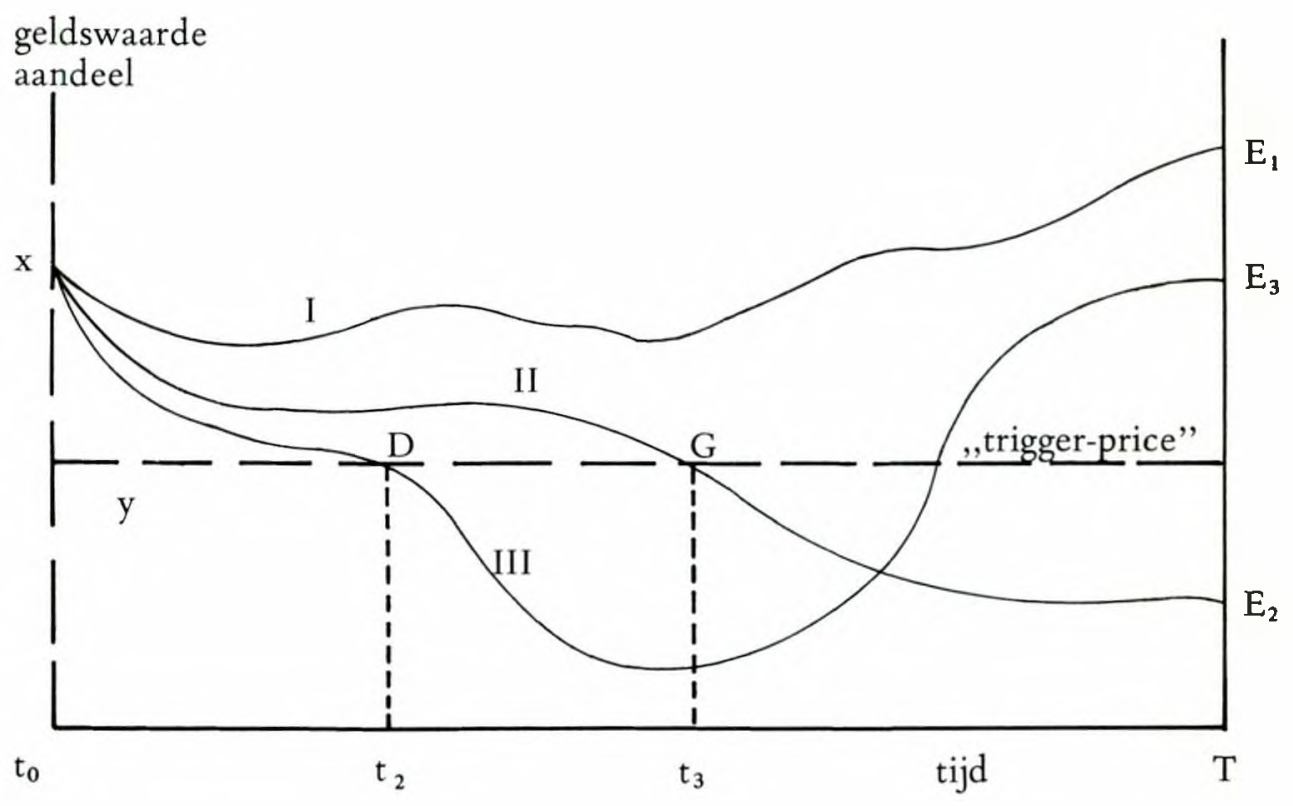

Wij nemen aan, dat de ,trigger-price" van de stop-loss-order gelijk is aan de obligatiewaarde (y) van de obligatie en dat de conversieverhouding één is, d.w.z. de waarde van het aandeel is dan gelijk aan de conversiewaarde ( $x$ ) van 
de obligatie. We gaan ervan uit, dat de conversiewaarde ligt boven de obligatiewaarde en dat deze conversiewaarde de beginwaarde is van het aandeel.

Met de lijnen I, II en III hebben wij drie mogelijke verlopen van de waarde van het aandeel tot het tijdstip $\mathrm{T}$ (het einde van de beschouwde periode) weergegeven.

Geval I De waarde van het aandeel of de conversiewaarde van de obligatie is gedurende de gehele periode groter dan de obligatiewaarde en eindigt met een waarde $\mathrm{E}_{1}$.

Geval II De waarde van het aandeel of de conversiewaarde van de obligatie heeft een dalend verloop en eindigt met een waarde, welke kleiner is dan de obligatiewaarde en eindigt met de waarde $E_{2}$.

Geval III De waarde van het aandeel of de conversiewaarde van de obligatie heeft aanvankelijk een dalend verloop tot zelfs onder de obligatiewaarde, maar eindigt met een waarde, welke boven de obligatiewaarde is gelegen en eindigt met een waarde $E_{3}$.

We gaan er vanuit, dat op tijdstip $t_{0}$ één converteerbare obligatie (omwisselbaar in één aandeel) en één aandeel voorzien van een stop-loss-order worden gekocht. We gaan dan na wat deze beide op tijdstip $\mathrm{T}$ opleveren in de verschillende gevallen; wat daarvan dus op tijdstip $T$ is overgebleven.

Indien het aandeel voorzien was geweest van een stop-loss-order, dan kunnen wij het resultaat bij het geschetste verloop van de waarde van het aandeel bezien in vergelijking met de converteerbare obligatie. In de gevallen I en II is het resultaat gelijk. Zowel met het aandeel voorzien van een stop-loss-order als met de obligatie eindigen wij in geval I met dezelfde eindwaarde $E_{1}$ en in het geval II met de obligatiewaarde. In geval II tonen beide hun verliesbeperkend karakter. De eindwaarde wordt in punt $G$ op het tijdstip $t_{3}$ voor het aandeel bereikt, terwijl de houder van de obligatie tot het tijdstip $\mathrm{T}$ kan wachten met het incasseren van de obligatiewaarde. Het verschil met de aandeelhouder, die in het bezit is van een aandeel voorzien van een stop-lossorder, is, dat de houder van de obligatie niet direkt op het tijdstip $t_{2}$ de obligatiewaarde hoeft te ontvangen, maar kan wachten tot het einde van de beschouwde periode.

In geval III echter eindigt de houder van de obligatie met de aandeelwaarde (conversiewaarde) $E_{3}$, welke hoger is dan de obligatiewaarde, terwijl de aandeelhouder voor zijn aandeel voorzien van een stop-loss-order in het gunstigste geval de lagere obligatiewaarde op het tijdstip $t_{2}$ (in het punt D) ontvangt. De aandeelhouder kan op het tijdstip $t_{2}$ de verkoopopbrengst van zijn aandeel weliswaar herinvesteren, maar dat doet niets af aan de vergelijking tussen de converteerbare obligatie en het aandeel voorzien van een stop-loss-order. Er treedt dan n.l. een nieuwe situatie in; het vergelijken kan opnieuw beginnen. In geval III is naar onze mening aannemelijk gemaakt, dat een aandeel voorzien van een stop-loss-order niet hetzelfde resultaat oplevert als de converteerbare obligatie. Beide beperken het verlies t.o.v. een aandeel zonder stop-loss-order, maar de stop-loss-order veroorzaakt ook een beperking van de winst (zijnde het verschil tussen de conversiewaarde $E_{3}$ en de obligatiewaarde). 
De converteerbare obligatie verkleint het risico van koersverlies, maar brengt in geval III meer op dan het aandeel voorzien van een stop-loss-order (welke in waarde niet verder komt dan de obligatiewaarde). Een aandeel voorzien van een stop-loss-order verkleint ook het risico van koersverlies, maar de verwachte opbrengst is kleiner dan de verwachte opbrengst van de obligatie. In geval II is het effect van de stop-loss-order opbrengstverhogend t.o.v. een aandeel, dat hiervan niet is voorzien, maar in geval III is het effect opbrengstverlagend.

\section{Conclusie}

De converteerbare obligatie kan het beste gekarakteriseerd worden aan de hand van het conversierecht en de garantie. Naar onze mening kan het bestaan van het verschijnsel premie het beste aannemelijk gemaakt worden met behulp van dit recht en deze garantie. Zowel garantie als conversierecht hebben de grootste betekenis, wanneer de verhouding obligatiewaarde en conversiewaarde dicht bij 1 ligt, waarmee wij aannemelijk hebben trachten te maken waarom de premie dan het hoogst is. Toetsing van deze opvatting aan de werkelijkheid zal de volgende stap moeten zijn. Een aandeel voorzien van een stop-loss-order heeft met de converteerbare obligatie gemeen, dat het verlies als gevolg van koersdaling beperkt kan worden, maar verschilt hierin met de obligatie, dat een winstbeperkend effect op de koop toe moet worden genomen.

\section{Geraadpleegde en aangehaalde literatuur}

1 Eugene F. Brigham, "An analysis of Convertible Debentures: Theory and some empirical evidence", in The Journal of Finance, maart 1966.

2 William J. Baumol, Burton G. Malkiel and Richard E. Quandt, „The valuation of convertible securities", in The Quarterly Journal of Economics, februari 1966.

3 Roman L. Weil, Joel E. Segall and David Green Jr., "Premiums on convertible bonds", in The Journal of Finance, juni 1968.

4 Paul D. Cretien Jr., „Premiums on convertible bonds: Comment", in 'The Journal of Finance, september 1970.

5 David Tell Duvel, "Premiums on convertible bonds: Comment", in The Journal of Finance, september 1970.

6 Otto H. Poensgen, "The valuation of convertible bonds", in Industrial Management Review, VII, no. 1 (Fall 1965) en idem, no. 2 (Spring 1966). 